\title{
Volatility Patterns of CDS, Bond and Stock Markets Before and During the Financial Crisis: Evidence from Major Financial Institutions
}

\author{
Ansgar Belke ${ }^{1,2,3}$ \& Christian Gokus ${ }^{1}$ \\ ${ }^{1}$ University of Duisburg-Essen, Germany \\ ${ }^{2}$ IZA, Bonn, Germany \\ ${ }^{3}$ Monetary Experts Panel, European Parliament, Brussels, Belgium \\ Correspondence: Ansgar Belke, University of Duisburg-Essen, Germany. Tel: 49-201-183-2776. E-mail: \\ Ansgar.belke@uni-due.de
}

Received: April 9, 2014

Accepted: May 1, 2014

Online Published: June 25, 2014

doi:10.5539/ijef.v6n7p53

URL: http://dx.doi.org/10.5539/ijef.v6n7p53

\begin{abstract}
This study is motivated by the development of credit-related instruments and signals of stock price movements of large banks during the recent financial crisis. What is common to most of the empirical studies in this field is that they concentrate on modeling the conditional mean. Surprisingly, only very few studies dealing with credit default swaps account for the characteristics of the variances. Our aim is to address this issue and provide insights on the volatility patterns of CDS spreads, bond yield spreads and stock prices. A multivariate GARCH is applied to the data of four large US banks over the period ranging from January 01, 2006 to December 31, 2009. With the commonly known shortcomings of credit ratings, the demand for market-based indicators has risen as they can help to assess the creditworthiness of debtors more reliably. The obtained findings suggest that volatility takes a significant higher level in times of crisis. This is particularly evident with respect to the variances of stock returns and CDS spread changes. Furthermore, correlations and covariances are time-varying and also increased in absolute values after the outbreak of the crisis, indicating stronger dependency among the examined variables. Specific events which have a huge impact on the financial markets as a whole (e.g., the collapse of Lehman Brothers) are also visible in the (co)variances and correlations as strong movements in the respective series.
\end{abstract}

Keywords: bond markets, credit default swaps, financial crisis, GARCH, stock markets, volatility

\section{Introduction}

The financial crisis that unfolded in summer 2007 has had a huge impact on a number of financial institutions in the United States and Europe. All institutions had to deal with an uncertain and more volatile market environment resulting in severely impaired overall performances. Consequently, concerns about the solvency of some large US and European financial institutions arose. The financial crisis has highlighted the fact that the accurate and timely evaluation of credit risk in companies, especially in large banks, is of utmost importance to avoid severe disruptions in the affected sectors. In particular, the bankruptcy of Lehman Brothers in September 2008 unfolded the consequences if the credit risk of large global financial players cannot be detected early enough.

Over the course of the crisis, the questionable behavior of rating agencies became an issue of high importance in public discussions. The information provided by credit rating agencies could not be regarded as a well-suited indicator of the creditworthiness of banks or e.g., the risk inherent in mortgage-backed securities. The risk was often underestimated which even intensified the crisis (Parnes, 2012). Furthermore, rating agencies are often too slow to provide a proper risk assessment of companies.

Investors as well as central banks and supervisory authorities are in need of market-based indicators to assess the soundness of the banking sector since bank failures can have devastating effects on the economy. When facing increased risk in financial institutions the question arises how the market can figure out changing risk profiles of these institutions. An interesting approach for identifying financial crises in general is provided by Parnes (2012). 
The author analyzes structural breaks in various economic variables to get information on the development of the US banking industry after the outbreak of the financial crisis in 2007. The results of this study imply that numerous structural changes lead to a permanent and robust shift in the US banking sector (Parnes, 2012).

However, a very straightforward approach is to gain important information by monitoring prices of bank securities. This price information provides a good yardstick for how market participants assess the risk of financial institutions (Persson \& Blavarg, 2003). Accordingly, our paper is motivated by the development of credit-related instruments and signals of stock price movements of large banks during the financial crisis.

The most prominent market indicators are probably the traditional instruments like stock prices and bond yield spreads. Over the recent years, the market for credit default swaps (CDS) has received special attention, as CDS should reflect pure credit risk of borrowers. The relationship between those variables has been subject to many empirical studies with the result that in particular the stock and the CDS market can quickly process credit-related information. For example Hull, Predescu and White (2004) show that CDS can even anticipate rating agency changes.

What is common to most of these studies is that they focus on modeling the conditional mean. Generally, financial time series exhibit certain stylized features such as volatility clustering and high kurtosis. In this paper we address this issue empirically to gain deeper insights on the volatility patterns of CDS spreads, bond yield spreads and stock prices. For this purpose, we apply a multivariate generalized autoregressive conditional heteroscedasticity (MGARCH) model to the data of four large US banks over the period from January 1, 2006, to December 31, 2009 in order to account for the dependency structure of the variables under consideration. Our empirical analysis provides evidence of strongly time-varying conditional covariances and correlations between the market-implied risk indicators and suggests that the empirical realizations of these measures have been exhibiting a substantially higher level during the financial crisis. This is especially true for the variances of the examined variables. Overall, the latter increase synchronously around specific events with a huge impact on financial markets such as, for example, the collapse of Lehman Brothers. However, the bond yield spread variances exhibit a slightly different pattern. An increased correlation in the course of the crisis could also be observed among the CDS spreads of the different banks.

Since volatility is often regarded as a measure of risk, the investigation of the second moments of the market implied risk indicators could provide additional information on the financial condition of the examined institutions as well as the financial system as a whole.

We organize the remainder of our paper as follows. In section 2 we develop some arguments why rating agencies might not be preferred by market participants as an early indicator of risk. In section 3 we present the theoretical background and the characteristics of certain market prices which are important providers of information concerning a firm's soundness according to the literature. Since the aim of our empirical analysis is to examine the volatility patterns of the identified variables, we present some literature on this issue in section 4 in conjunction with some hypotheses to be tested later on. Section 5 reports the results of a detailed empirical investigation of the volatility patterns of the risk indicators which also includes the dependency structure. Evidence is provided for specific commercial banks using a multivariate GARCH approach. Section 6 concludes and summarizes our main results.

\section{Rating Agencies and the Need for Market-Based Indicators}

In general, credit ratings provide information on the relative creditworthiness of issuers as well as their issued debt. Although default risk cannot be measured precisely, the standardized risk categories make it possible to compare issuers (Micu, Remolona, \& Wooldridge, 2004). The information provided by credit rating agencies are considered as an important input for the decision-making of investors in credit markets and serve as a fundamental input to different kinds of credit risk models (for instance the pricing model of Jarrow, Lando and Turnbull (1997)). Pension funds and other institutional investors rely heavily on the assessment of credit risk, as they are legally bound to hold only investment grade bonds. Therefore, various market participants are concerned about changes in credit ratings, since they can raise the capital costs of issuers, influence credit spreads and bond returns as well as the prices of credit derivatives (Kou \& Varotto, 2005).

Although rating agencies play a very important role in the economy, they often reveal some shortcomings in the timely and accurate assessment of debtors' credit risk. One problem is the weak performance of credit ratings as an early indicator of potential risk. Another critical issue is the potential conflict of interest which arises due to the fact that debtors pay the agencies to evaluate their debt. Especially during the subprime crisis starting in mid-2007 the validity of credit ratings were questioned by market participants (see for instance Brunnermeier, 2009 or Calomiris, 2009). 
Due to the above mentioned shortcomings of credit ratings, the demand for market-based indicators has risen, as they can help to assess the creditworthiness of debtors more reliable. Market-based indicators can potentially react immediately to macroeconomic or company related news, whereas rating agencies need some time to process new information (Di Cesare, 2006). The usefulness of market information for policy purposes has already been acknowledged. For instance, the term structure of interest rates or implied volatilities have been used in the decision-making process of monetary policy and supervisory authorities (Annaert, De Ceuster, Van Roy, \& Vespro, 2013).

Daniels and Jensen (2005) find that the bond and the CDS market can anticipate credit rating changes (downgrades better than upgrades). Furthermore, in this respect the CDS market reacts faster than the bond market. These results confirm the findings by Hull et al. (2004) who also underline the ability of CDS spreads to anticipate rating announcements. Analyzing the informational content of the stock and CDS market, Norden and Weber (2004) show that both markets anticipate rating changes.

In principal, CDS spreads are perceived as a measure of pure credit risk which may serve as a benchmark for measuring and pricing credit risk and may suit the needs of a credit risk proxy better than corporate bonds (Abid \& Naifar, 2006; Norden \& Weber, 2009). Nevertheless, bond spreads and equity prices should not be neglected in the analysis of credit risk. Stocks, like bonds, are claims on a firm and therefore default risk should be reflected by market prices on these claims.

\section{Linking Bond Spreads to CDS Spreads and Stock Prices}

Movements in corporate bond spreads reflect market expectations of how the credit outlook of firms will be in the future. The spreads are usually calculated as the difference between the risky corporate bond yields and the yields on government bonds or swap yields which are proxies for the risk-free interest rate (Note 1). Thus, the spreads on corporate bonds are the risk premium corporations have to pay the investors as a compensation for several risks inherent in corporate debt, for instance, default risk, liquidity risk and prepayment risk (Alexopoulou, Andersson, \& Georgescu, 2009).

A theoretical relationship between CDS and bond spreads can be derived from reduced-form models (Note 2). The equality relationship between both spreads can easily be established by means of the risk neutral default probability as well as no-arbitrage conditions. The underlying reasoning has been proposed by Duffie (1999) and Hull and White (2000). In this case, the risk-free interest rate is constant over time. Buying a CDS for protection purposes requires a payment of a constant premium until a default occurs (or any other predefined credit event) or the contract matures. If the firm defaults, the protection seller has to pay the difference between the face value and the market value of the reference obligation.

Considering the no-arbitrage conditions, it is possible to replicate the credit default swap synthetically by shorting a bond with fixed coupon at par on the same reference entity with the same maturity date. The returns should then be invested in a par risk-free note with fixed coupon. As a result, the CDS premium and the credit spread of the par bond with fixed coupon should be equal. Deviations from this parity enable to make arbitrage profits (Zhu, 2006).

Nevertheless, various reasons may hinder the parity relationship to hold in practice. The deviation from the equivalence of CDS and bond spreads can be explained by the failure of some of the underlying assumptions in reality, e.g., non-constancy of the risk-free interest rate.

The considerations above illustrate the close relationship between CDS and bond spreads if certain restrictive assumptions are satisfied. However, some advantages of CDS spreads in comparison to bond spreads can be identified (Annaert et al., 2013). Bond spreads are calculated as the difference between risky bonds and a risk-free interest rate, i.e. they have to be computed first and cannot be observed directly, in contrast to CDS spreads. Moreover, the identification of the credit premium in the spreads of risky bonds is probably contaminated by liquidity (Chen, Lesmond, \& Wei, 2007), tax effects (Elton, Gruber, Agrawal, \& Mann, 2001) and microstructure effects.

The equity market is regarded as a very important provider of information for a firm's soundness. To illustrate how bond and equity prices are related, Merton (1974) proposes a theoretical framework which makes use of the option-pricing theory. The model shows that equity prices and bond spreads are highly connected and should move in opposite directions. To draw a connection to the CDS market, the close relationship of bond and CDS spreads suggests that credit default swap spreads and equity prices should also disperse (Chan-Lau \& Kim, 2004). Looking at two major banks such as Goldman Sachs and Citigroup, it becomes obvious from the data that the spreads and stock prices move in opposite directions (see Figure 1). 

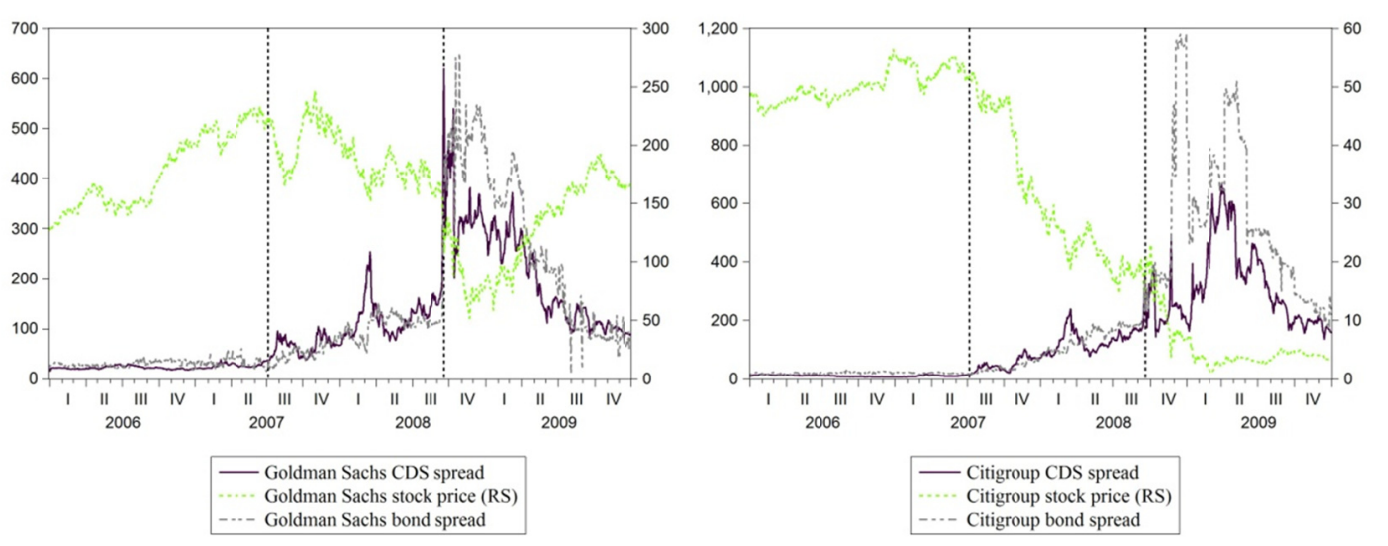

Figure 1. CDS spreads, bond spreads and stock prices of selected financial institutions

Note. Bond spreads are spreads over the swap curve with 5 year maturity. Bond spreads and CDS spreads are on the left axis in bp, stock prices on the right scale (RS) in US dollar. Dotted vertical lines are at 6/30/2007 (approximate start of the crisis) and 9/15/2008 (failure of Lehman Brothers); Data source: Thomson Reuters Datastream.

\section{Related Literature and Derived Hypotheses}

Financial time series exhibit certain stylized features such as volatility clustering or time-varying correlations which cannot be grasped sufficiently by models based on the assumption of homoscedasticity (Schreiber, Müller, Klüppelberg, \& Wagner, 2012). However, very few studies dealing with credit default swaps account for the characteristics in the variances.

Scheicher (2009) analyzes conditional correlations between stock returns and changes in CDS premia for a sample of 240 firms covering the years 2003-2005. The author shows in a bivariate EWMA framework that periods of market turbulence lead to strong increases in these correlations and that correlations among individual firms are substantially volatile. An overall negative correlation between CDS spread changes and equity returns can be observed without considerable differences between US and European samples. The time-varying negative correlation does also hold for investment grade and high-yield segments of the credit market. The finding of a negative correlation supports the results of Norden and Weber (2009) and Kwan (1996) who also documents a significant negative relation between stock prices and corporate debt.

Schreiber et al. (2012) fit two different VAR-GARCH approaches (BEKK and DCC parameterization) and investigate the conditional covariance structure by using daily data of the iTraxx Europe, Euro Stoxx 50 and VStoxx index over the period June 2004 to April 2009.They detect a strong variation over time in the conditional variances and correlations. In particular, the authors find the correlations between the iTraxx and the Euro Stoxx, and the Euro Stoxx and the VStoxx to be negative. A positive correlation exists between the iTraxx and the VStoxx. In addition, a significant increase in the absolute values of the correlations can be observed after the start of the subprime crisis.

Meng, ap Gwilym and Varas (2009) are interested in the volatility transmission among the bond, CDS and equity markets. Their study should help to shed light on the efficiency of the respective markets. The authors use return data of the three variables for ten large US companies in a multivariate GARCH (BEKK) approach over the period 2003-2005. They find little support for the hypothesis that the CDS market is the originator of volatility transmission to the equity and bond market. Rather, they confirm that the link between the markets has strengthened. The almost reciprocal volatility spillover supports the view that innovations in one market can influence the other markets as investors are in search for high yield across different assets. Accordingly, shocks originating in one market can cause increased trading activity in the two other markets. Therefore, regulators should keep in mind the strong linkage between the CDS, bond and equity markets.

The empirical literature dealing with volatility patterns of the CDS, bond and equity markets disclose that certain characteristics can be observed regarding the correlations and (co)variances over time. All studies reveal that the conditional (co)variances for the different variables are strongly time-varying and especially in turbulent times are on a much higher level (cf. Schreiber et al., 2012). The same pattern could be observed for the conditional correlations between the CDS and stock market, and the bond and stock market. This suggests that the 
correlations are not overall constant over time and should become more pronounced during the period after the start of the subprime crisis. Accordingly, our first hypothesis runs as follows:

\section{H1: The conditional (co)variances vary over time with correlations taking higher levels during the crisis period.}

Furthermore, the obvious structural break in the original series (see Figure 1) should also be present in the conditional (co)variances. As stated by Coudert and Gex (2010), volatility will generally increase in times of crisis, a view which is supported by other studies (cf. Scheicher, 2009). Especially around the date of the collapse of Lehman Brothers, strong movements should be visible in the covariances and variances. Coudert and Gex (2010) even use volatility patterns in the CDS market to identify the start of a crisis period (in this case the GM and Ford crisis in 2005). Since CDS spreads, stock prices and bond yield spreads should fundamentally represent the financial condition of a company, events affecting the financial outlook of the firm should also be observed in the volatility of all three variables.

H2: Variances and covariances of CDS spreads, bond yield spreads and stock prices move in a similar fashion due to credit-related events affecting a company.

Actually, a co-movement of volatilities may hint at the fact that the different markets are affected by the same economic shock.

In the recent past, the market for credit default swaps has received special attention in the analysis of credit risk. CDS spreads are widely regarded as an important indicator of potential default risk and, what is more, CDS spreads may be used as a complement to credit ratings. Credit default swap premia increased dramatically in the course of the financial crisis. As Rhaman (2009) and Coudert and Gex (2010) persuasively reassure, the correlations between CDS spreads of different institutions should also increase in turbulent times which may indicate contagion effects.

H3: Correlations between CDS spreads of different companies increase with the start of the financial crisis.

\section{Empirical Analysis}

\subsection{Data}

The empirical analysis is based on data for CDS spreads, bond yields, and equity prices of four large US financial institutions: Bear Stearns, Citigroup, Goldman Sachs and Merrill Lynch. Hence, our sample contains banks which were under severe distress during the financial crisis. Especially Bear Stearns and Merrill Lynch had been hit very badly by the crisis and were then taken over by other large banks. These institutions have been chosen because of their importance in the financial markets due to their (former) large market power.

The whole sample period covers the years from January 2006 to December 2009 and is characterized by a tranquil phase (pre-crisis period) at the beginning of the sample period (January 1, 2006, to mid-2007) in which the CDS and the bond spreads maintained a rather low level and stock prices were still on a high level. The second phase is characterized by high volatility and uncertainty after mid-2007 (crisis period).

The data for credit default swaps consists of daily mid-CDS spreads for the reference entities expressed in basis points (bp). Senior debt CDS with a maturity of 5 years have been chosen, since they are the most liquid maturity segment. CMA (Credit Market Analysis) quotes were retrieved from Thomson Reuters Datastream (Note 3).

One problem which arises when comparing 5-year CDS spreads and bond yield spreads is the fact that it is nearly impossible to find a corporate bond which matches the 5-year constant maturity of the CDS contracts. In order to solve this problem, a synthetic bond has to be constructed following the methodology of Blanco, Brennan and Marsh (2005) and Norden and Weber (2009) (Note 4). To build the 5-year risky corporate bond, the daily yields (redemption yields) of two bonds were linearly interpolated. For this purpose, one bond with 3 to 5 years left to maturity at the beginning of the sample period and one bond with more than 5 years to maturity also at the start of the sample has been used. All bonds are straight bonds with fixed coupons, and only bonds in the currency of the CDS were considered.

The bond yield spreads can be calculated by subtracting the risk-free interest rate from the synthetic 5-year constant bonds. As noted by Houveling and Vorst (2005), government bonds, which are usually used, may not be the appropriate benchmark rate. For example, investors in the derivative market generally rely on the swap curve in their decisions (Blanco et al., 2005) (Note 5). These data were then used to construct the generic spread to match the 5-year maturity. All series are denominated in US Dollars and applied in log-differences in order to obtain stationarity. Furthermore, preliminary tests suggest that a GARCH model which is described in the following section is appropriate (Note 6). 


\subsection{Econometric Methodology and Estimation Results}

In order to capture the simultaneous volatility clustering and to gain important insights into the co-movement of financial time series, univariate GARCH models have been extended to the multivariate case (for an extensive survey on multivariate GARCH models see Silvennoinen and Teräsvirta (2009) or Bauwens, Laurent and Rombouts (2006)). Modeling the conditional covariance structure is especially important in asset pricing, risk management and can also help to analyze volatility and correlation spillover and transmission effects (Silvennoinen \& Teräsvirta, 2009). In addition, the strong linkage of the CDS, bond and equity market described above makes it reasonable to use a multivariate GARCH framework for the analysis of the volatility patterns.

The model structure can be described as follows:

$$
\begin{gathered}
r_{t}=\mu_{t}+\varepsilon_{t} \\
\varepsilon_{t}=H_{t}^{1 / 2} v_{t}, \quad v_{t}=i . i . d . \\
\varepsilon_{t} \mid \Omega_{t-1} \sim N\left(0, H_{t}\right)
\end{gathered}
$$

where $r_{t}$ represents a vector of returns (in this case stock, CDS and bond returns), whereas $\mu$ is a $N \times 1$ vector and contains the parameters that estimate the mean of the return series. The vector $\varepsilon_{t}$ equals the residuals with the corresponding conditional covariance matrix $H_{t}$, given the available information set $\Omega_{t-1} \cdot v_{t}$ is a white noise error term. The multivariate form of the GARCH model requires the specification of the covariance matrix $H_{t}$.

For this purpose, Engle and Kroner (1995) define the BEKK model. This model reduces the number of parameters to be estimated compared to other multivariate GARCH specifications and especially the positive definiteness of the conditional covariance matrix is guaranteed by construction (Baur, 2006; Silvennoinen \& Teräsvirta, 2009). The unrestricted first order BEKK-GARCH(1,1) model may be written as follows:

$$
H_{t}=C^{\prime} C+A^{\prime} \varepsilon_{t-1} \varepsilon_{t-1}^{\prime} A+B^{\prime} H_{t-1} B
$$

where $C, A$ and $B$ are $N \times N$ parameter matrices, and $C$ is upper triangular (Tsay, 2006). One can easily see from equation (4) that $H_{t}$ is positive definite as long as the diagonal elements of $C$ are positive. This is due to the quadratic formulation of the conditional variance equation. A further simplification can be achieved by restricting the matrices $A$ and $B$ to be diagonal which will be used in the following.

Although the excess kurtosis inherent in the returns series would suggest a Student's t-distribution for the estimation to account for the fat tails, financial time series are often skewed and therefore the application of a Student's t distribution may be questioned (Schreiber et al., 2012).

The subsequent empirical analysis makes use of an AR(1) model plus constant for the conditional mean. It appears to be an adequate representation of the mean in order to account for the autocorrelation which is partly existent in the time series and should guarantee appropriate estimates for the conditional (co)variances.

The Akaike (AIC) and Schwarz (SIC) information criteria as well as the value of the maximized likelihood function were used to test for the appropriate model order. Table 1 contains the results of different specifications for the diagonal BEKK model.

Table 1. Model order selection for $\operatorname{AR}(1)-\operatorname{BEKK}(p, q)$ for $p, q=1,2$, whole sample period

\begin{tabular}{llllll}
\hline & Criterion & $\operatorname{BEKK}(1,1)$ & $\operatorname{BEKK}(1,2)$ & $\operatorname{BEKK}(2,1)$ & $\operatorname{BEKK}(2,2)$ \\
\hline \multirow{2}{*}{ Bear } & AIC & -8.752 & -8.922 & -8.401 & -8.451 \\
Stearns & SIC & -8.624 & -8.773 & -8.252 & -8.281 \\
& ML & 2770.391 & 2826.927 & 2663.044 & 2681.817 \\
& AIC & -9.135 & -9.144 & -9.141 & -9.047 \\
Citigroup & SIC & -9.050 & -9.044 & -9.041 & -8.933 \\
& ML & 4781.962 & 4789.646 & 4787.893 & 4741.782 \\
\multirow{3}{*}{ Goldman } & AIC & -8.873 & -8.920 & -8.894 & -8.744 \\
Sachs & SIC & -8.788 & -8.820 & -8.794 & -8.631 \\
& ML & 4645.488 & 4672.771 & 4659.136 & 4584.209 \\
Lynchill & AIC & -9.375 & -9.447 & -9.431 & -9.308 \\
& SIC & -9.268 & -9.322 & -9.306 & -9.165 \\
& ML & 3683.788 & 3714.795 & 3708.645 & 3663.409 \\
\hline
\end{tabular}

Note. AIC $=$ Akaike information criterion, $\mathrm{SIC}=$ Schwarz information criterion, $\mathrm{ML}=$ value of the maximized likelihood function; Data source: Thomson Reuters Datastream. 
The results indicate that a $\operatorname{BEKK}(1,2)$ or a $\operatorname{BEKK}(2,1)$ specification would be appropriate to model the volatility patterns of the return series. However, adding additional ARCH or GARCH terms to the specification improves the model only slightly, especially when comparing AIC and SIC of the different models. Furthermore, many researchers dealing with financial time series have shown that $\operatorname{GARCH}(1,1)$ specifications often proved to be sufficient to yield efficient and significant results (see for instance Bollerslev, Chou and Kroner, 1992). Therefore, the model order was deliberately held simple and the following estimation results were obtained from the estimation of a diagonal $\operatorname{BEKK}(1,1)$ specification.

The estimation output for the whole sample period is presented in Table 2. The upper panel of the table presents the coefficient estimates of the mean equations, whereas the second panel shows the variance equation estimates for the different entities. The corresponding ML, AIC and SIC values can be found in Table 1. The $\omega$ values in the mean equations are all nearly zero and for the most part insignificant. However, the main focus of the analysis is on the variance estimations which overall show highly significant estimates for the variance and covariance coefficients.

Table 2. Estimation results of the diagonal BEKK $(1,1)$ model

\begin{tabular}{|c|c|c|c|c|}
\hline & Bear Stearns & Citigroup & $\begin{array}{c}\text { Goldman } \\
\text { Sachs }\end{array}$ & $\begin{array}{l}\text { Merrill } \\
\text { Lynch }\end{array}$ \\
\hline$\omega_{s t}$ & $\begin{array}{l}0.001 * \\
(1.631)\end{array}$ & $\begin{array}{c}0.000 \\
(0.640)\end{array}$ & $\begin{array}{c}0.002 * * * \\
(2.787)\end{array}$ & $\begin{array}{c}0.001 \\
(1.594)\end{array}$ \\
\hline$\varphi_{s t}$ & $\begin{array}{c}0.006 \\
(0.138)\end{array}$ & $\begin{array}{c}-0.024 \\
(-0.889)\end{array}$ & $\begin{array}{c}-0.102 * * * \\
(-3.850)\end{array}$ & $\begin{array}{c}-0.068 * * \\
(-2.117)\end{array}$ \\
\hline$\omega_{c d s}$ & $\begin{array}{c}0.001 \\
(0.305)\end{array}$ & $\begin{array}{c}-0.001 \\
(-0.656)\end{array}$ & $\begin{array}{c}-0.001 \\
(-0.809)\end{array}$ & $\begin{array}{c}0.000 \\
(-0.146)\end{array}$ \\
\hline$\varphi_{c d s}$ & $\begin{array}{c}-0.004 \\
(-0.115)\end{array}$ & $\begin{array}{c}0.003 \\
(0.130)\end{array}$ & $\begin{array}{c}0.036 \\
(1.327)\end{array}$ & $\begin{array}{c}0.031 \\
(1.003)\end{array}$ \\
\hline$\omega_{b o}$ & $\begin{array}{c}0.003 \\
(0.503)\end{array}$ & $\begin{array}{l}0.004 * \\
(1.644)\end{array}$ & $\begin{array}{c}-0.001 \\
(-0.546)\end{array}$ & $\begin{array}{l}0.006^{*} \\
(1.865)\end{array}$ \\
\hline$\varphi_{b o}$ & $\begin{array}{c}-0.260^{* * *} \\
(-5.814)\end{array}$ & $\begin{array}{c}-0.291 * * * \\
(-9.049)\end{array}$ & $\begin{array}{c}-0.257^{* * *} \\
(-7.349)\end{array}$ & $\begin{array}{c}-0.233 * * * \\
(-7.497)\end{array}$ \\
\hline$c_{11}$ & $\begin{array}{c}0.000^{* * * *} \\
(6.501)\end{array}$ & $\begin{array}{c}0.000 * * * \\
(3.618)\end{array}$ & $\begin{array}{c}0.000 * * * \\
(5.396)\end{array}$ & $\begin{array}{c}0.000^{* * *} \\
(2.781)\end{array}$ \\
\hline$c_{12}$ & $\begin{array}{c}0.000 * * * \\
(-2.633)\end{array}$ & $\begin{array}{c}0.000 \\
(-0.167)\end{array}$ & $\begin{array}{c}0.000 * * * \\
(-3.326)\end{array}$ & $\begin{array}{l}0.000^{* *} \\
(-1.992)\end{array}$ \\
\hline$c_{13}$ & $\begin{array}{c}0.000 \\
(1.136)\end{array}$ & $\begin{array}{c}0.000 \\
(0.539)\end{array}$ & $\begin{array}{c}0.000 \\
(0.256)\end{array}$ & $\begin{array}{c}0.000^{* * *} \\
(2.587)\end{array}$ \\
\hline$c_{22}$ & $\begin{array}{c}0.000 * * * \\
(4.868)\end{array}$ & $\begin{array}{c}0.000 * * * \\
(10.493)\end{array}$ & $\begin{array}{c}0.000^{* * *} \\
(9.112)\end{array}$ & $\begin{array}{c}0.000^{* * *} \\
(7.619)\end{array}$ \\
\hline$c_{23}$ & $\begin{array}{c}0.000 \\
(0.021)\end{array}$ & $\begin{array}{c}0.000 \\
(-0.488)\end{array}$ & $\begin{array}{c}0.000^{* * *} \\
(0.618)\end{array}$ & $\begin{array}{c}0.000 \\
(-0.536)\end{array}$ \\
\hline$c_{33}$ & $\begin{array}{c}0.002 * * * \\
(3.465)\end{array}$ & $\begin{array}{c}0.002 * * * \\
(5.623)\end{array}$ & $\begin{array}{c}0.001 * * * \\
(11.304)\end{array}$ & $\begin{array}{c}0.000^{* * *} \\
(5.663)\end{array}$ \\
\hline$a_{11}$ & $\begin{array}{c}0.940 * * * \\
(49.275)\end{array}$ & $\begin{array}{c}0.317 * * * \\
(22.208)\end{array}$ & $\begin{array}{c}0.223 * * * \\
(19.434)\end{array}$ & $\begin{array}{c}0.277 * * * \\
(13.830)\end{array}$ \\
\hline$a_{22}$ & $\begin{array}{c}0.358 * * * \\
(23.105)\end{array}$ & $\begin{array}{c}0.298 * * * \\
(25.784)\end{array}$ & $\begin{array}{l}0.300 * * * \\
(26.987)\end{array}$ & $\begin{array}{c}0.344 * * * \\
(19.918)\end{array}$ \\
\hline$a_{33}$ & $\begin{array}{c}0.162 * * * \\
(6.106)\end{array}$ & $\begin{array}{c}0.295 * * * \\
(8.128)\end{array}$ & $\begin{array}{c}0.632 * * * \\
(41.706)\end{array}$ & $\begin{array}{c}0.297 * * * \\
(21.284)\end{array}$ \\
\hline$b_{11}$ & $\begin{array}{c}0.640 * * * \\
(32.584)\end{array}$ & $\begin{array}{l}0.953 * * * \\
(266.620)\end{array}$ & $\begin{array}{l}0.972 * * * \\
(389.427)\end{array}$ & $\begin{array}{l}0.964 * * * \\
(170.947)\end{array}$ \\
\hline$b_{22}$ & $\begin{array}{l}0.935 * * * \\
(158.126)\end{array}$ & $\begin{array}{l}0.944 * * * \\
(326.331)\end{array}$ & $\begin{array}{l}0.942 * * * \\
(279.098)\end{array}$ & $\begin{array}{l}0.928^{* * *} \\
(141.833)\end{array}$ \\
\hline$b_{33}$ & $\begin{array}{c}0.938^{* * *} \\
(51.591)\end{array}$ & $\begin{array}{c}0.805 * * * \\
(21.579)\end{array}$ & $\begin{array}{l}0.846 * * * \\
(162.082)\end{array}$ & $\begin{array}{l}0.957 * * * \\
(243.447)\end{array}$ \\
\hline Nobs & 629 & 1043 & 1043 & 782 \\
\hline
\end{tabular}

Note: $* * *, * *, *$ indicate significance at the $1 \%, 5 \%$ and $10 \%$ level. Z-statistics are in parenthesis. Nobs are number of observations. $1=$ st, 2 = cds, $3=$ bo. 
The estimated parameters of the means in the variance and covariance equations $(c)$ do not differ substantially from zero. The coefficients $b_{i i}$ capture the influence of lagged values of the conditional variances $h_{i i}$ on the conditional variance today. Accordingly, the larger the coefficient $b_{i i}$, the longer is the effect of the shocks. Moreover, high values of $b_{i i}$ capture the volatility clustering. In other words, high values of $h_{t-l}$ will be followed by high values of $h_{t}$.

The estimated coefficients for $b_{i i}$ are all higher than 0.90 for all three variables across the examined institutions. Exceptions are the bond market coefficients for Goldman Sachs and Citigroup where $b_{33}$ only exceeds 0.80 which nevertheless is a high value. Moreover, the conditional variances of the three variables for all institutions are significantly affected by the ARCH parameters $a_{i i}$ which range from 0.162 to 0.940 but the value is mostly in a range of approximately $0.22-0.36$. The results indicate that news/shocks $\left(\varepsilon_{t-1}\right)$ in the previous period play a minor role in determining the conditional variances and covariances compared to past own values which describe the influence of older information $\left(\varepsilon_{t-2}, \varepsilon_{t-3}\right.$, etc.).

Only the stock returns of Bear Stearns ( $a$ value of 0.94$)$ and the bond spread changes of Goldman Sachs ( $a$ value of 0.623 ) have higher values, indicating that the respective variances are driven to a larger extent by the lagged error term. This means that, for instance, stock returns of Bear Stearns are more prone to news from yesterday. Furthermore, information shocks from two or more periods ago are less relevant. This persistence can also be observed in the conditional covariances. If this is not the case, the volatility or covariance processes would probably be misspecified (Baur, 2006). The overall significant results for the covariance equations indicate covariation in shocks.

Considering the magnitude of the coefficient estimates of the matrices $A$ and $B$ and keeping the condition for covariance stationarity in mind which states in the case of the diagonal BEKK model that $\sum_{k-1}^{n}\left(a_{i i, k}^{2}+b_{i i, k}^{2}\right)<1$ $\forall i=1, \ldots, N$, the covariance stationarity condition is often rejected (Note 7). Similar results are obtained by Schreiber et al. (2012) who also observe an integrated covariance $H_{t}$ for a period including the financial crisis for the variables Euro Stoxx 50, iTraxx Europe and the VStoxx. A (nearly) integrated behavior of volatilities could be the result of structural changes and therefore may reflect other dynamics for volatility. It has been suggested by, for instance, Hamilton and Susmel (1994) that an almost integrated volatility process may indicate that the true model for volatility is a regime-switching model.

Figure 2 displays the estimated conditional correlations between the stock returns and CDS spread changes, stock returns and bond spread changes as well as CDS and bond spread changes. The first obvious aspect is the strong time variation of all correlations. The apparent structural break in Figure 1 due to the outbreak of the subprime crisis in mid-2007 is also visible in the conditional correlations (cf. dotted vertical line at 6/30/2007). A second strong movement in the conditional correlations can be observed around 9/15/2008 (Lehman Brothers, second dotted vertical line).

The correlations between CDS spread changes and stock returns became more negative after the first break. This can also be observed after the date of the Lehman Brothers failure. These results are quite intuitive, as they imply that falling stock returns tend to be followed by increasing CDS spread changes (CDS spreads widen) and vice versa. This pattern is also reported by Scheicher (2009) and Schreiber et al. (2012).

The conditional correlations between bond yield spread changes and stock returns show that a former more or less positive conditional correlation turned negative with the outbreak of the crisis and after a reversion again around the Lehman collapse in September 2008. At least during the crisis the negative relation between bond spread changes and stock returns holds. The conditional correlations for Bear Stearns and Merrill Lynch are overall positive for stock returns and bond yield spreads. The positive correlations might be explained by firm-specific factors. More volatile firm profits affect bond and equity holders differently due to its impact on the likelihood of default. A higher volatility of profits would drive down bond prices (spreads increase) and potentially increase stock prices at the expense of bond holders. Takeover risk is another factor which potentially influences the relation between stock returns and bond yield spreads (Bhanot, Mansi, \& Wald, 2010). 
Conditional correlation stocks vs. CDS
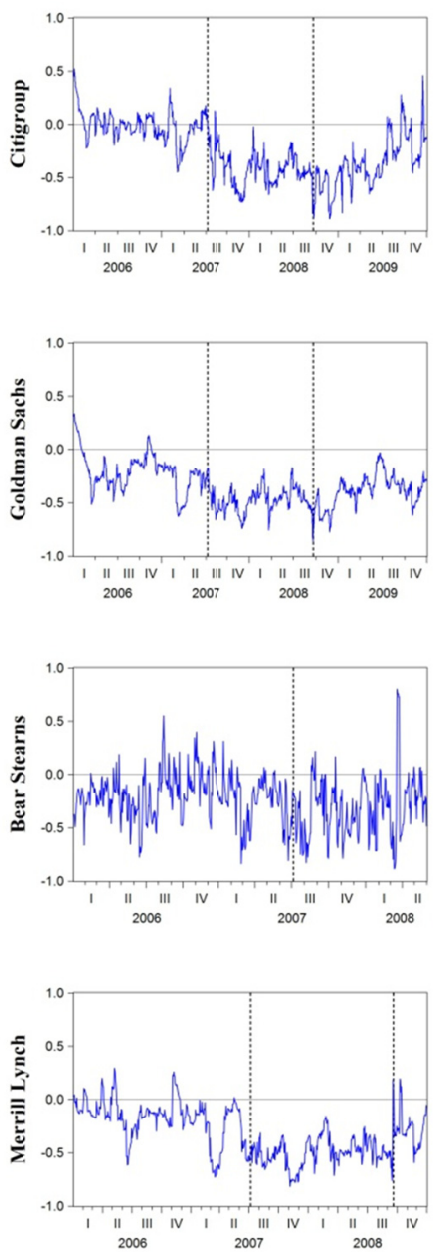

Conditional correlation stocks vs. bonds
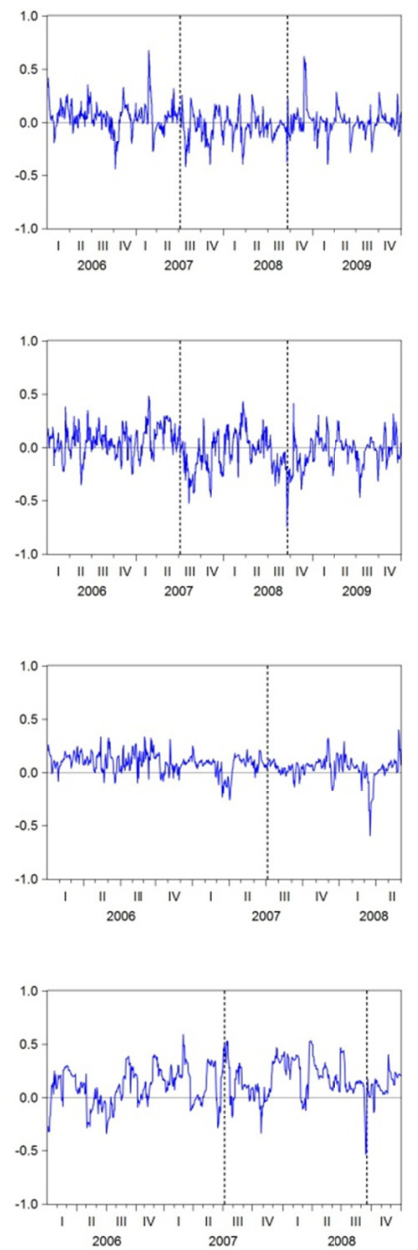

Conditional correlation CDS vs. bonds
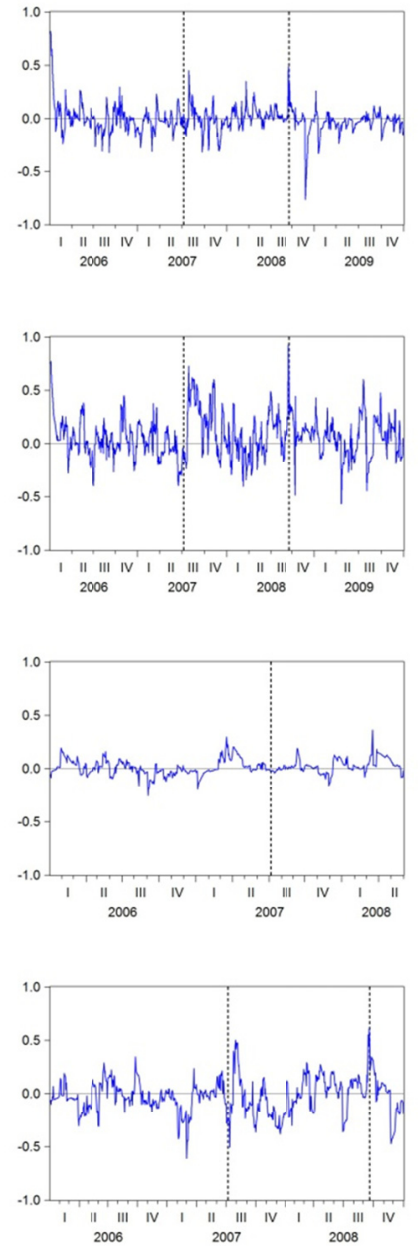

Figure 2. Conditional correlations

Note. Dotted vertical lines are at 6/30/2007 (approximate start of the crisis) and 9/15/2008 (failure of Lehman Brothers); Data source: Thomson Reuters Datastream.

The conditional correlations between CDS and bond spread changes are also highly fluctuating with more or less strong increases at the specific dates (except for Bear Stearns). The positive correlation especially at the start of the crisis and before September 2008 implies that at least around these events increasing CDS spreads tend to be followed by increasing bond yield spreads or vice versa. In other words, both spreads widen, especially when the economic outlook is bad, indicating that market participant expect higher risk in the examined banks.

The movements in conditional correlations suggest that the three variables are interconnected. In particular, the correlations increased in absolute terms since the start of the crisis. This is only partly true for Bear Stearns. This might be explained by the severe problems Bear Stearns was confronted with after they announced the suspension of payments of a large hedge fund in summer 2007 and the early adjustment of the creditworthiness by market participants.

Figure 3 and Figure 4 depict the conditional variances and covariances of the stock returns as well as CDS and bond spread changes. 
Conditional variance stocks
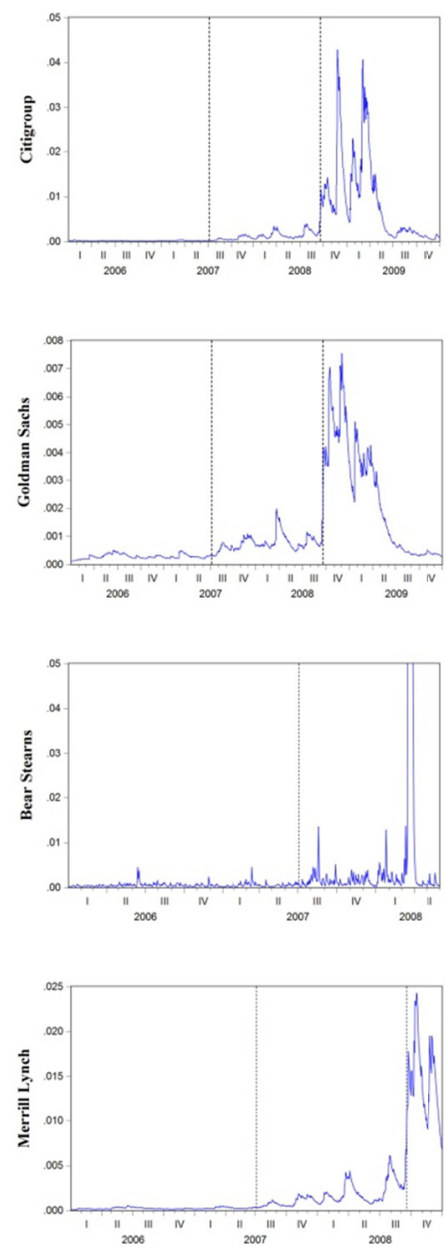

Figure 3. Conditional variances

Conditional covariance stocks vs. CDS
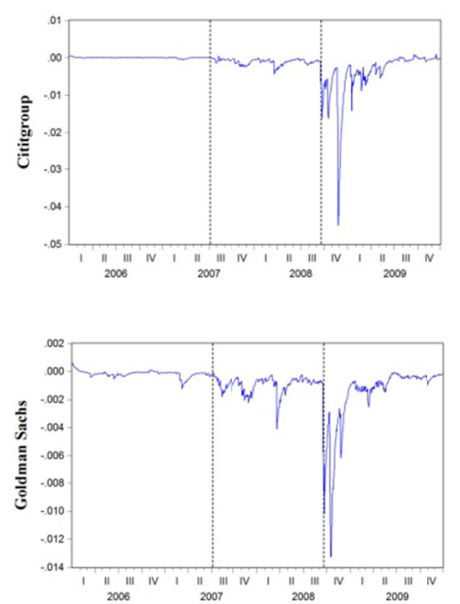

Conditional covariance stocks vs. bonds
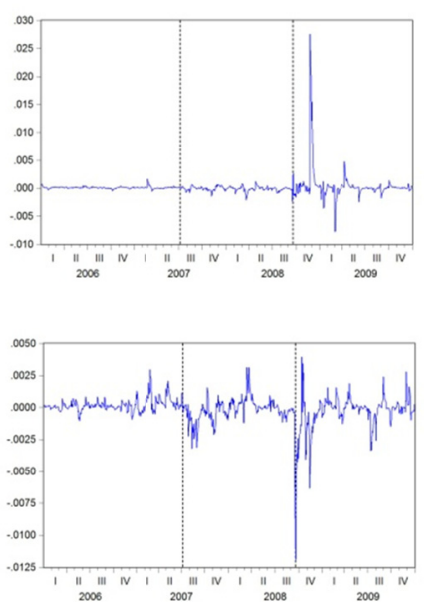

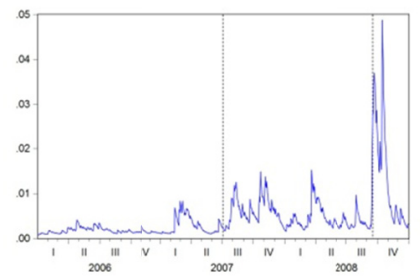

Conditional variance CDS
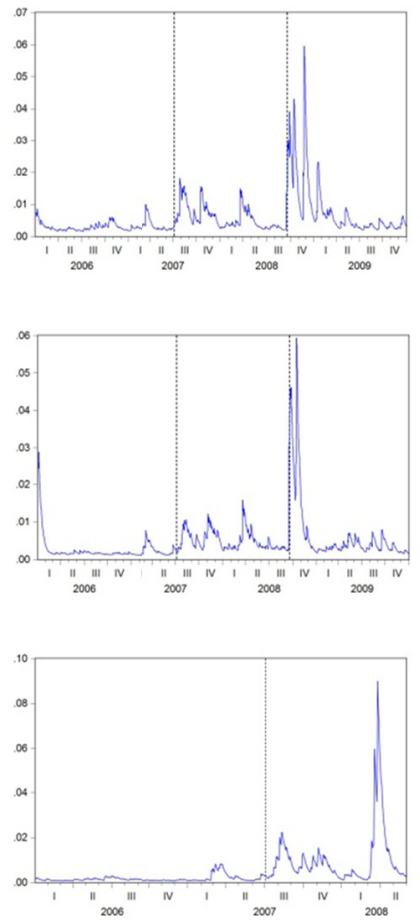

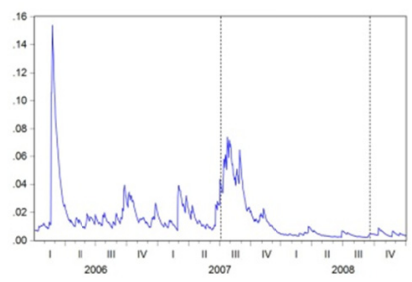

Conditional variance bonds
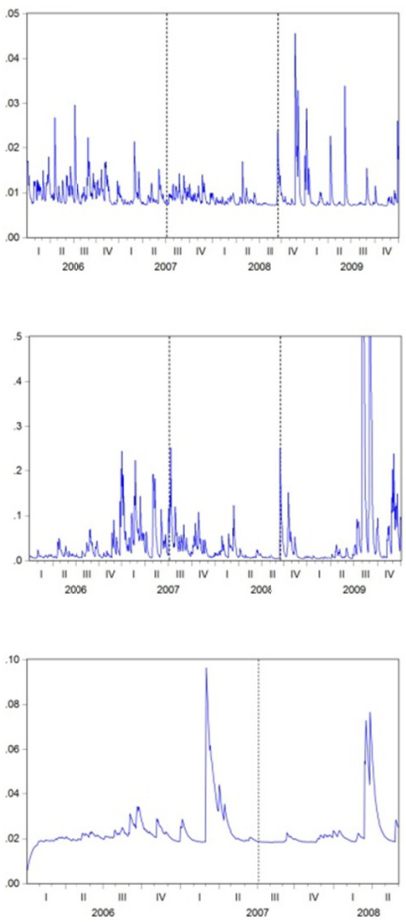

Conditional covariance CDS vs. bonds
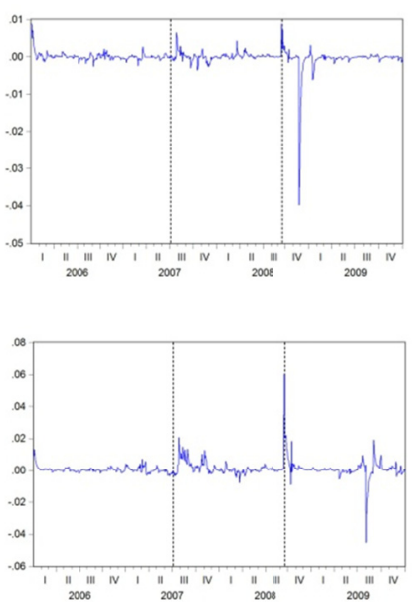

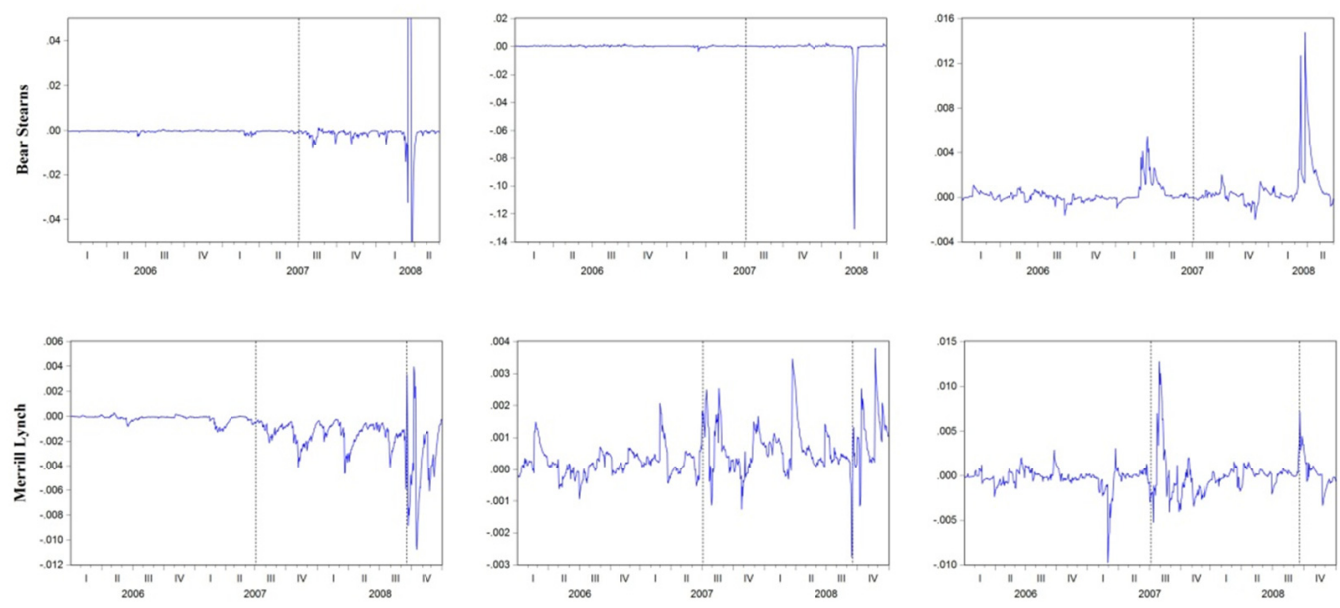

Figure 4. Conditional covariances

Note. Dotted vertical lines are at 6/30/2007 (approximate start of the crisis) and 9/15/2008 (failure of Lehman Brothers); Data Source: Thomson Reuters Datastream.

All variances and covariances vary strongly over time and a break in the series can be observed in mid-2007 (approximate start of the subprime crisis) and in particular in September 2008 (collapse of Lehman Brothers). After the outbreak of the crisis, the variations in the variances and covariances are more pronounced and are overall on a higher level. They reach their maximum after the Lehman Brothers' failure which point to the huge impact of this event.

Moreover, the covariances tend to be higher (lower) in times of high (low) volatility. These results are consistent with Schreiber et al. (2012) for CDS spreads and stocks, and de Goeij and Marquering (2004) for stock and bond returns. If the time-variation in covariances is only due to variation in the variances, the conditional correlations have to be zero. However, considering the estimated correlations in Figure 2, it is obvious that these are not constant over time, indicating that the variability in covariances is not only due to changes in variances (de Goeij \& Marquering, 2004).

Especially the variances of the stock returns and credit default swap changes of the different institutions show a clear pattern during the crisis period. Before the failure of Lehman Brothers, three peaks in the CDS variances can be observed, coinciding with certain events which had a huge impact on financial markets. The first peak can be attributed to the liquidation of two Bear Stearns hedge funds that invested in various types of mortgage-backed securities on July 31, 2007. Since mid October 2007 financial market pressure intensified after the announcement of Citigoup, Bank of America and JPMorgan Chase that they planned to purchase highly rated assets from existing special purpose vehicles and the Fed announced to reduce the target rate. Moreover, at the start of November 2007, liquidity in the interbank funding market dried up which may contribute to the second peak in the (co)variances. The third peak before the Lehman Brothers failure approximately on 14 March, 2008 coincides with the announcement of JP Morgan to purchase Bear Stearns (Fed of St. Louis, 2010). Those events are also visible in the stock return variances but not as pronounced. Furthermore, after Lehman Brothers, the variances of the stock returns remained on a very high level until mid-2009, whereas the volatility of the CDS spread changes decreased relatively quickly. Accordingly, the stock markets were very anxious at that time and did not expect the turbulence to come to an end for an extended period (see Figure 5). 

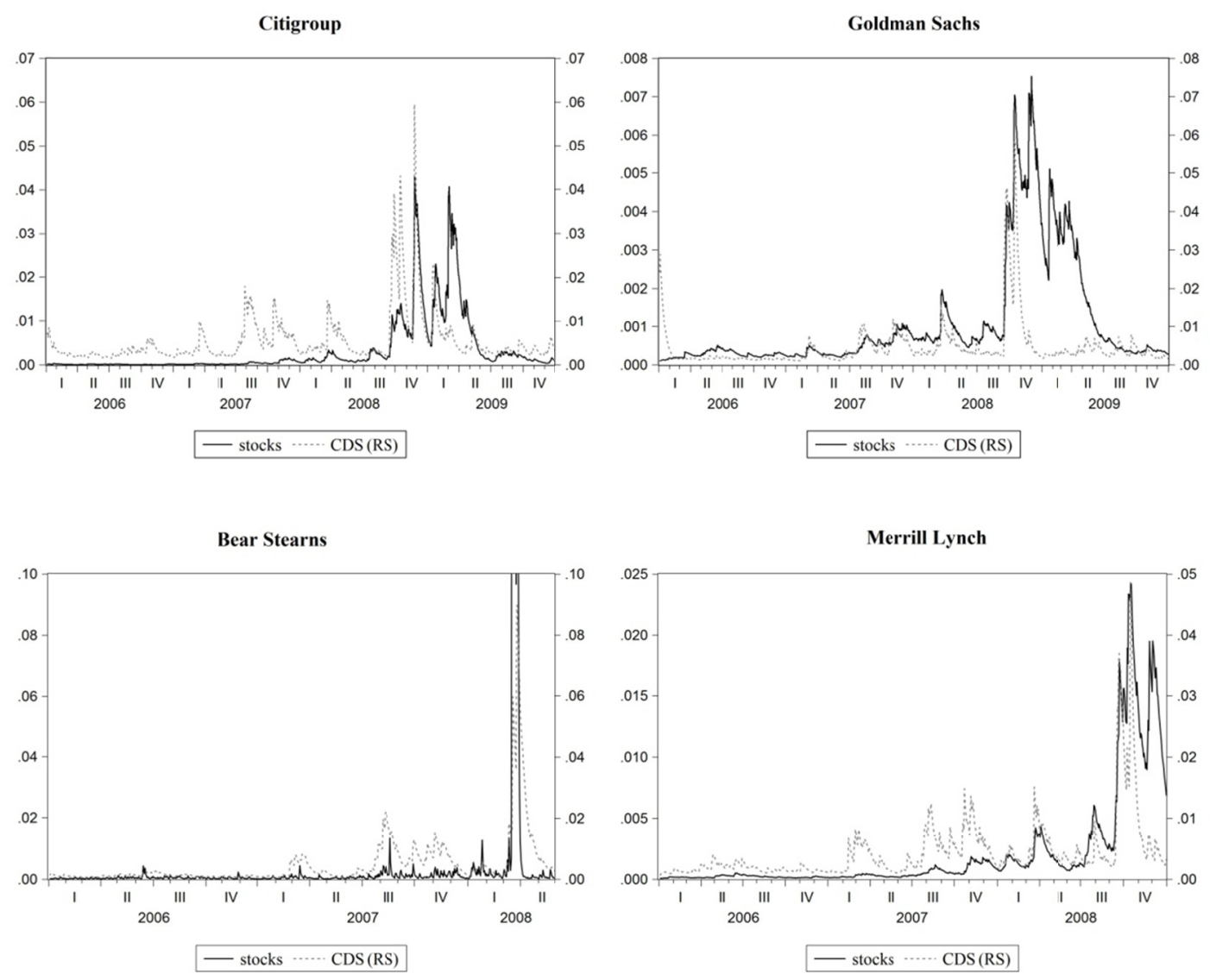

Figure 5. Comparison of selected stock and CDS variances

Note. The stock variance is on the left scale, CDS variance on the right scale (RS); Data source: Thomson Reuters Datastream.

Although the variances in the bond spread changes do also exhibit the peaks to some extent, they are not as clear-cut as in the other series. It seems that they are determined by other factors as well. This can be seen, for instance, by the jump in the variances at the end of 2009 and the comparably high volatility before the start of the crisis that is not present in the variances of stock returns or CDS spread changes.

The covariances between stock returns and CDS spreads become significantly negative during the crisis with particularly large values in September 2008 and the already observed peaks around the above mentioned dates. This suggests that higher values of the CDS spread changes tend to be paired with lower values of stock returns and that the dependency became stronger at the economically important events. This pattern is partly obvious in the covariance between stock returns and bond spread changes, but again, different forces seem to influence the series. The covariances between CDS and bond spread changes became more positive around the events but generally, a clear pattern cannot be identified (sometimes large negative values). Around the bankruptcy of Lehman Brothers, all variances and covariances jumped dramatically across all institutions and sometimes reverting former relations (e.g., the high positive values in the covariance of stocks and bonds) emphasizing the huge impact of this event on the financial markets. Overall, the graphical inspection of the covariances and variances implies that major shocks in the financial sector as a whole can be detected in the increasing values across all investigated institutions. Nevertheless, it is hard to make any proposition about the soundness of a single entity from the analysis above, since it is not an easy task to distinguish between idiosyncratic shocks and common financial market-related shocks.

To summarize, the results for the whole sample period strongly support hypothesis $H 1$ that all (co)variances and correlations are strongly varying over time with higher levels after the start of the crisis. In addition, hypothesis $H 2$ can be corroborated for the most part. Variances of CDS spread changes and stock returns reacted similar to shocks occurring in financial markets, whereas the bond spread changes might be influenced by other factors as well. This is also true for the covariances including bond spread changes. The bad performance of bond spread 
changes could also be explained by the already mentioned factors that influence those spreads. A drawback is the often rejected covariance stationarity condition of the volatility processes and the often insignificant parameter estimates of the mean in the covariance equations. Dividing the whole sample in two sub-periods gives further support for hypothesis $H 1$ (Note 8).

\subsection{Correlations Within the CDS Market}

During times of crisis it is a well-documented phenomenon that asset returns become more correlated. This increased co-movement might be explained by a higher correlation in the fundamental values. In the case of CDS, these fundamentals can be, for instance, the components of the Merton model. However, to define fundamentals properly is a point of debate in any market. An alternative explanation of the increased co-movement is contagion (Anderson, 2010). Contagion effects are important, since they do generally imply positive default correlations (Jorion \& Zhang, 2007).

This section assesses the dependence structure between the financial institutions' CDS spreads. Compared to bonds, CDS spreads often perform better in the measurement of borrowers' creditworthiness, since they are not affected by tax or liquidity effects. Additionally, they could serve as the market's perception of credit risk (Rahman, 2009). Reasons for a joint occurrence of credit events or a deterioration of credit quality of different entities can be cyclical shocks, market-wide adverse factors or close linkages. The close linkage between institutions is often referred to as contagion and is favorable to an increased dependence structure (Rahman, 2009). Therefore, it would be interesting to see, how the credit default swap spreads of the different institutions have evolved over the whole period, as rising correlations are often considered as the key determinant of contagion (Coudert \& Gex, 2010). Coudert and Gex (2010) show that the correlation within the CDS market increases during crisis periods and they state that this could be a hint of contagion. Especially in the banking sector, it is assumed that large institutions are highly connected.
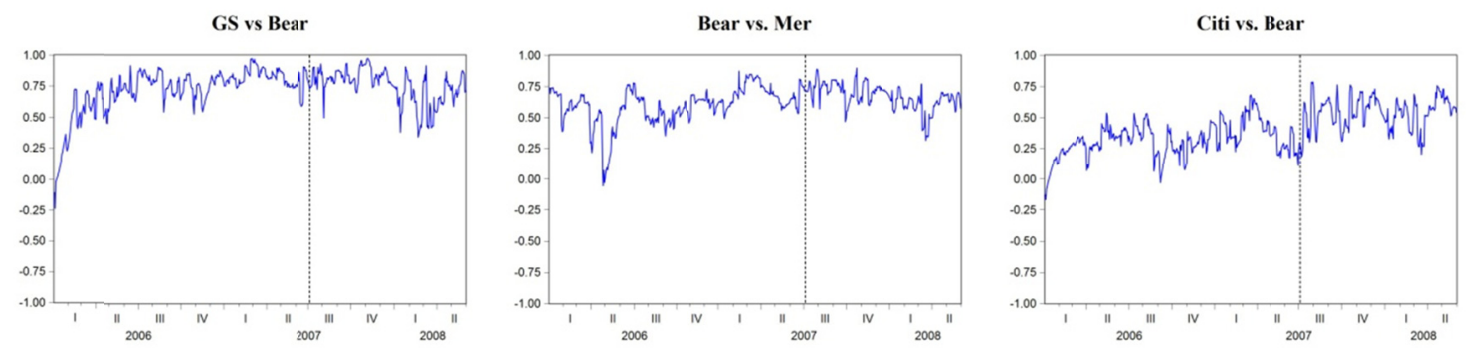

Citi vs. GS
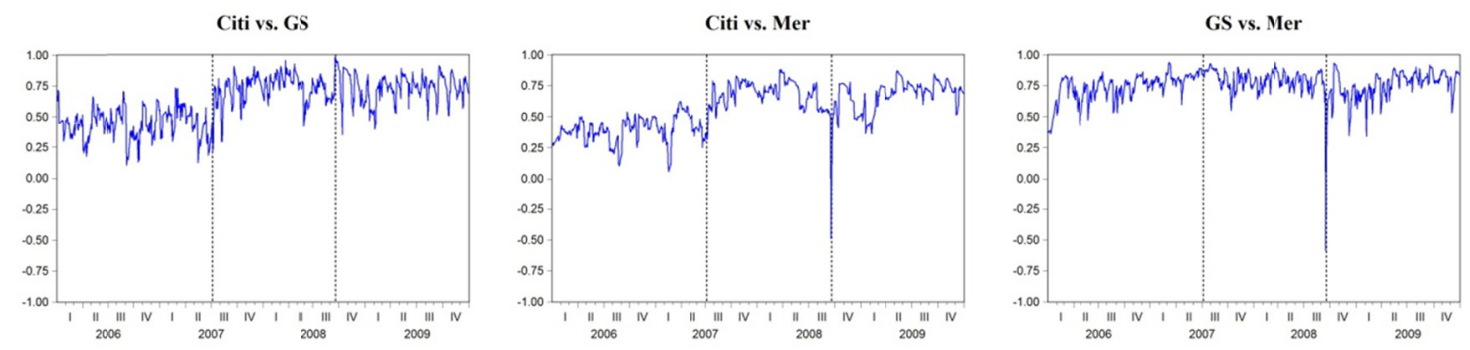

Figure 6. Conditional correlations between the institutions' CDS spreads

Note. Conditional correlations between Bear Stearns and the other institutions end at May 31, 2008. Dotted vertical lines are at 6/30/2007 (approximate start of the crisis) and 9/15/2008 (failure of Lehman Brothers). Bear = Bear Stearns, Citi = Citigroup, GS = Goldman Sachs, Mer = Merrill Lynch; Data source: Thomson Reuters Datastream.

Figure 6 illustrates the estimated conditional correlations between all entities obtained from a bivariate diagonal $\operatorname{BEKK}(1,1)$ model. The estimation was also conducted with an $\operatorname{AR}(1)$ term in the mean equation to account for the autocorrelation in the series (Note 9). It is obvious from Figure 6 that the conditional correlations between the CDS spreads of the investigated institutions are overall on a rather high level and strongly time-varying. The conditional correlations between Bear Stearns and Goldman Sachs as well as Bear Stearns and Merrill Lynch do only show a slight increase in correlations around the approximate start of the subprime crisis. This may be due to the already existing very high correlations between those institutions which fluctuate mostly in a range 
between 0.5 and 1. The same is true for the conditional correlations between Goldman Sachs and Merrill Lynch. This implies that those banks are already highly interconnected with regard to credit default swaps even before the start of the financial crisis.

A shift around mid-2007 is visible in the conditional correlations of Citigroup and Goldman Sachs, Citigroup and Merrill Lynch, and Citigroup and Bear Stearns. The correlations were higher after the outbreak of the crisis (approximately 0.25 points higher), indicating that the crisis had a perceptible impact on the relation between CDS spread changes of different banks. Another unusual movement can be observed in mid-September 2008, when the conditional correlations between Citigroup and Merrill Lynch, and Goldman Sachs and Merrill Lynch became negative for a short period of time only to jump back on an even higher level afterwards. This again points to the huge distorting impact of the collapse of Lehman Brothers.

All in all, a clear cut in the conditional correlations is visible around mid-2007 with increasing correlations afterwards which confirm hypothesis H3. Given the importance of the analyzed institutions, it seems that investors reassessed the risks attached to all borrowers. These results support findings by Coudert and Gex (2010) who find increased correlations between CDS spread changes during the GM and Ford crisis in 2005 and results obtained by Anderson (2010) for the recent financial crisis. Both studies attribute this development to contagion effects. It is not possible from the analysis above to make a statement if fundamental factors potentially play a role in the increased correlations. Nevertheless, it seems very reasonable to conclude from Figure 6 and the findings obtained by the other studies that contagion effects are the drivers of the increased correlations. The understanding of the dynamics in the CDS market has important implications for supervisory authorities and risk management practitioners (Rahman, 2009).

\subsection{Diagnostic Testing}

After fitting the diagonal $\operatorname{BEKK}(1,1)$ model to the data, the appropriateness can be evaluated using a number of graphical and statistical diagnostics on the standardized residuals. A closer look at the standardized residuals clearly show that much of the volatility pattern in the original return series can be captured by the diagonal $\operatorname{BEKK}(1,1)$ model, although some outliers are still present (Figure 7).

Particularly in the CDS and bond spread changes, the impact of the Lehman Brothers failure is still obvious indicated by large outliers. Overall, the graphical inspection suggests that the diagonal BEKK model was able to capture a significant part of the volatility structure of the data set (Schreiber et al., 2012).

Standardized residuals stocks
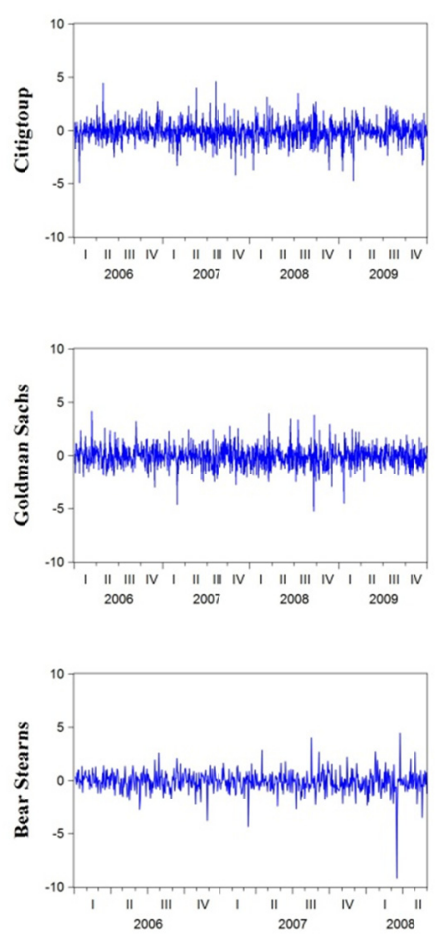

Standardized residuals CDS
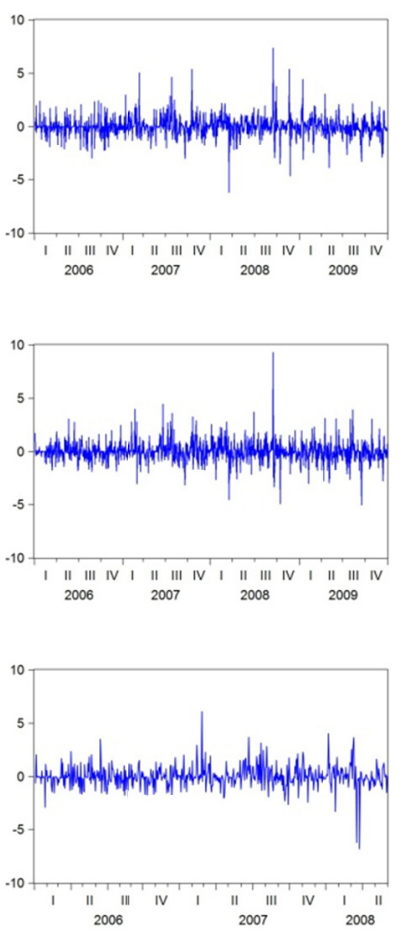

Standardized residuals bonds
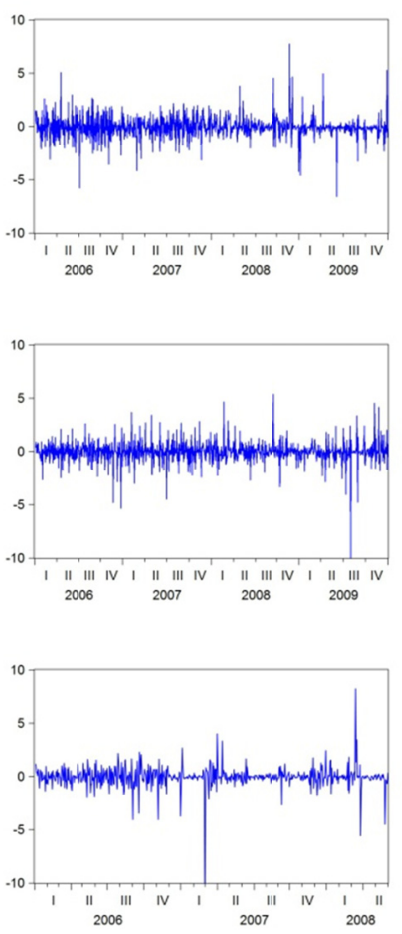

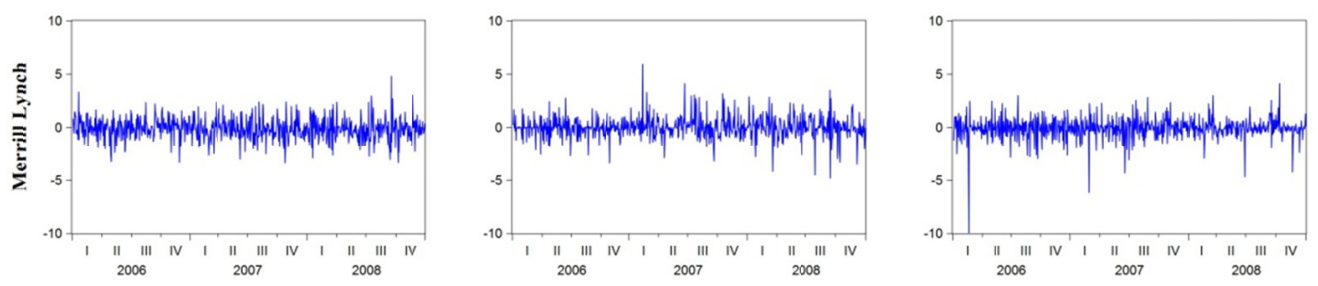

Figure 7. Standardized residuals

The Ljung-Box test statistic of remaining autocorrelation in the standardized and squared standardized residuals corroborates the visual inspection. The results are presented in Table 3, indicating that the null hypothesis of no autocorrelation cannot be rejected for most of the series. Overall, the fit of the model seems to be appropriate.

Table 3. Ljung-Box statistics for standardized and squared standardized residuals

\begin{tabular}{lllllllllllll}
\hline & \multicolumn{3}{l}{ Bear Stearns } & \multicolumn{4}{c}{ Citigroup } & \multicolumn{3}{c}{ Goldman Sachs } & \multicolumn{3}{c}{ Merrill Lynch } \\
\cline { 2 - 14 } & Stock & CDS & Bond & Stock & CDS & Bond & Stock & CDS & Bond & Stock & CDS & Bond \\
\hline $\mathrm{LB}(4)$ & 0.8 & $13.0^{* *}$ & 3.5 & 4.5 & 3.0 & $14.1^{* * *}$ & 6.7 & 2.5 & $18.6^{* * *}$ & 6.1 & 4.7 & $14.6^{* * *}$ \\
$\mathrm{LB}(12)$ & $19.4^{*}$ & $19.3^{*}$ & 14.9 & 10.6 & 9.7 & $27.7^{* * *}$ & 10.9 & 7.6 & $33.4^{* * *}$ & $21.3^{*}$ & 12.1 & $21.0^{*}$ \\
$\mathrm{LB}^{2}(4)$ & 5.8 & 1.2 & 0.4 & $8.2^{*}$ & 6.5 & 0.1 & $58.5^{* * *}$ & $12.4^{* *}$ & 2.2 & $27.0^{* * *}$ & 7.1 & 0.9 \\
$\mathrm{LB}^{2}(12)$ & $34.3^{* * *}$ & $79.6^{* * *}$ & 3.8 & 10.4 & 10.4 & 7.8 & $62.0^{* * *}$ & 13.6 & 5.5 & $32.7^{* * *}$ & 9.2 & 1.6 \\
\hline
\end{tabular}

Note. ${ }^{* *}, * *, *$ indicate significance levels at $1 \%, 5 \%$ and $10 \%$, respectively. Ljung-Box test of autocorrelation up to lag 36 . The numbers in parenthesis stand for the respective lags. $\mathrm{LB}^{2}$ is the test applied to squared standardized residuals; Data source: Thomson Reuters Datastream.

All in all, the graphical inspection and the results of the Ljung-Box statistic suggest that the applied multivariate $\operatorname{AR}(1)-G A R C H(1,1)$ captures the structure in the second order moments of the time series pretty well, but was not able to capture all outliers and remaining autocorrelation (Note 10). Overall, it can be concluded that the diagonal BEKK $(1,1)$ model is able to capture most of the noise in the original series for the considered specifications.

The empirical analysis provides evidence on the time variation in the variances and covariances of all variables and across all institutions. This has strong implications for portfolio selection, asset pricing and risk management models (Schreiber et al., 2012) which make use of the (co)variation of variables. The same holds for the conditional correlations.

But more importantly, as the variables under consideration represent a measure of bank's risk, a uniform reaction of the institutions risk indicators following a common market shock implies that the bank is confronted with mounting financial problems. This co-movement could also be observed in the second moments of all three variables, in particular in the stock and CDS series. For instance, if market participants are increasingly concerned about the future performance of a bank, they start to buy CDS contracts as an insurance against a possible default. In doing so, CDS spreads as well as the volatility will rise due to the more active trading (Meng et al., 2009). A similar reasoning can be applied to stock returns. Therefore, monitoring the volatility additionally provides useful information with regard to risks in the banking sector. Particularly during the very turbulent crisis period the volatility seems to be mainly driven by events with a huge impact on the financial market as a whole. This can be seen by the simultaneous increase in the (co)variances of all variables and across all institutions.

\section{Conclusions}

Stock returns, CDS spreads and bond spreads are regarded as an appropriate market-based alternative for credit rating agencies to detect risk in banks timelier and in a more reliable fashion. Employing a multivariate GARCH approach, we have examined the volatility patterns of the former variables. This econometric framework allows us to model the stylized features of financial time series and additionally accounts for the dependency structure between them. For this purpose, we have investigated a data set of four large US banks over the period ranging from January 1, 2006, to December 31, 2009.

The obtained findings support the view that volatility turns out to take higher levels in times of crisis. This is 
particularly evident in the variances of stock returns and CDS spread changes. Furthermore, correlations and covariances are time-varying and have also increased in absolute values after the outbreak of the crisis, indicating stronger dependency of the examined variables. Specific events which have a huge impact on the financial markets as a whole (e.g., the collapse of Lehman Brothers) are also visible in the (co)variances and correlations by means of strong movements in the respective series. This pattern suggests that common factors drive the volatilities of the market-implied indicators. Certain events can also be observed in the (co)variances of bond spread changes. But the latter time series seem to be influenced by other factors as well. Moreover, our investigation of the CDS spread changes of the different banks delivers evidence of increased correlations during the crisis period which is indicative of contagion effects.

Overall, it appears thus that the multivariate GARCH framework fits the data reasonably well. Nevertheless, in order to capture the dynamics during the very turbulent crisis period and the obvious structural breaks in the (co)variance series, there is some scope to adopt, for instance, a (multivariate) Markov-switching GARCH model.

The soundness of banks is a crucial factor for financial stability as a prerequisite for economic growth. Our volatility analysis sheds light on the development of the (co)variances of prominent market-implied risk indicators, particularly during the financial crisis. The latter appear to be predominantly driven by common market shocks. Although accurately predicting a bank's failure remains a challenging task, we have shown that analyzing the volatility patterns of CDS spreads, bond spreads and stock prices gives valuable insights for supervising authorities and central banks when evaluating possible financial risks.

\section{Acknowledgments}

We are grateful for valuable comments from Ingo Bordon, Daniel Gros and Diego Valiante.

\section{References}

Abid, F., \& Naifar, N. (2006). The Determinants of Credit Default Swap Rates: An Explanatory Study. International Journal of Theoretical and Applied Finance, 9(1), 23-42. http://dx.doi.org/10.1142/S0219024906003445

Alexopoulou, I., Andersson, M., \& Georgescu, O. M. (2009). An Empirical Study on the Decoupling Movements between Corporate Bond and CDS Spreads. ECB Working Paper Series, 1085, European Central Bank, Frankfurt/Main.

Anderson, M. (2010). Contagion and Excess Correlation in Credit Default Swaps. Working Paper, Department of Finance, Fisher College of Business, Ohio State University. http://dx.doi.org/10.2139/ssrn.2023043

Annaert, J., De Ceuster, M., Van Roy, P., \& Vespro, C. (2013). What Determines Euro Area Bank CDS Spreads? Journal of International Money and Finance, 32, 444-461. http://dx.doi.org/10.1016/ j.jimonfin.2012.05.029

Baur, D. (2006). A Flexible Dynamic Correlation Model. In T. B. Fomby \& D. Terrell (Eds.), Econometric Analysis of Financial and Economic Time Series (pp. 3-31). Amsterdam.

Bauwens, L., Laurent, S., \& Rombouts J. V. K. (2006). Multivariate GARCH Models: A Survey. Journal of Applied Econometrics, 21(1), 79-109. http://dx.doi.org/10.1002/jae.842

Bhanot, K., Mansi, S. A., \& Wald, J. K. (2010). Takeover Risk and the Correlation Between Stocks and Bonds. Journal of Empirical Finance, 17(3), 381-393. http://dx.doi.org/10.1016/j.jempfin.2009.10.006

Blanco, R., Brennan, S., \& Marsh, I. W. (2005). An Empirical Analysis of the Dynamic Relation between Investment-Grade Bonds and Credit Default Swaps. The Journal of Finance, 60(5), 2255-2281. http://dx.doi.org/10.1111/j.1540-6261.2005.00798.x

Bollerslev, T. (1986). Generalized Autoregressive Conditional Heteroscedasticity. Journal of Econometrics, 31(3), 307-327. http://dx.doi.org/10.1016/0304-4076(86)90063-1

Bollerslev, T., Chou, R. Y., \& Kroner, K. F. (1992). ARCH modeling in finance: A review of the theory and empirical evidence. Journal of Econometrics, 52(1-2), 5-59. http://dx.doi.org/10.1016/0304-4076(92)90064-x

Brunnermeier, M. K. (2009). Deciphering the 2007-2008 Liquidity and Credit Crunch. Journal of Economic Perspectives, 23, 77-100. http://dx.doi.org/10.1257/jep.23.1.77

Calomiris, C. W. (2009). The Subprime Turmoil: What's Old, What's New and What's Next. The Journal of Structured Finance, 15, 6-52. http://dx.doi.org/10.3905/JSF.2009.15.1.006 
Chan-Lau, J. A., \& Kim, Y. S. (2004). Equity Prices, Credit Default Swaps, and Bond Spreads in Emerging Markets. IMF Working Papers, WP/04/27, International Monetary Fund, Washington, DC.

Chen, L., Lesmond, D. A., \& Wei, J. (2007). Corporate Yield Spreads and Bond Liquidity. Journal of Finance, 62(1), 119-149. http://dx.doi.org/10.1111/j.1540-6261.2007.01203.x

Coudert, V., \& Gex, M. (2010). Contagion Inside the Credit Default Swap Market: The Case of the GM and Ford Crisis in 2005. Journal of International Financial Markets, Institutions and Money, 20(2), 109-134. http://dx.doi.org/10.1016/j.intfin.2010.01.001

Daniels, K. N., \& Jensen, M. S. (2005). The Effect of Credit Ratings on Credit Default Swap Spreads and Credit Spreads. Journal of Fixed Income, 15(3), 16-33. http://dx.doi.org/10.3905/jfi.2005.605421

De Goeij, P., \& Marquering, W. (2004). Modeling the Conditional Covariance Between Stock and Bond Returns: A Multivariate GARCH Approach. Journal of Financial Econometrics, 2(4), 531-564. http://dx.doi.org/10.1093/jjfinec/nbh021

Di Cesare, A. (2006). Do Market-based Indicators Anticipate Rating Agencies? Evidence for International Banks. Economic Notes by Banca Monte dei Paschi di Siena SpA, 35(1), 121-150. http://dx.doi.org/10.1111/j.0391-5026.2006.00161.x

Duffie, D. (1999). Credit Swap Valuation. Finance Analysts Journal, 55(1), $73-87$. http://dx.doi.org/10.2469/faj.v55.n1.2243

Elton, E. J., Gruber, M. J., Agrawal, D., \& Mann, C. (2001). Explaining the Rate Spread on Corporate Bonds. Journal of Finance, 56(1), 247-277. http://dx.doi.org/10.1111/0022-1082.00324

Engle, R. F., \& Kroner, K. F. (1995). Multivariate Simultaneous Generalized ARCH. Econometric Theory, 11(5), 122-150. http://dx.doi.org/10.1017/S0266466600009063

Federal Reserve Bank of St. Louis. (2010). The Financial Crisis: A Timeline of Events and Policy Actions. Retrieved September 12, 2010, from http://timeline.stlouisfed.org

Hamilton, J. D., \& Susmel, R. (1994). Autoregressive Conditional Heteroskedasticity and Changes in Regime. Journal of Econometrics, 64(1-2), 307-333. http://dx.doi.org/10.1016/0304-4076(94)90067-1

Houveling, P., \& Vorst, T. (2005). Pricing Default Swaps: Empirical Evidence. Journal of International Money and Finance, 24(8), 1200-1225. http://dx.doi.org/10.1016/j.jimonfin.2005.08.009

Hull, J., \& White, A. (2000). Valuing Credit Default Swaps I: No Counterparty Default Risk. Journal of Derivatives, 8(1), 29-40. http://dx.doi.org/10.3905/jod.2000.319115

Hull, J., Predescu, M., \& White, A. (2004). The Relationship between Credit Default Swap Spreads, Bond Yields, and Credit Rating Announcements. Journal of Banking and Finance, 28(11), 2789-2811. http://dx.doi.org/10.1016/j.jbankfin.2004.06.010

Jarrow, R. A., Lando, D., \& Turnbull, S. M. (1997). A Markov Model for the Term Structure of Credit Risk Spreads. The Review of Financial Studies, 10(2), 481-523. http://dx.doi.org/10.1093/rfs/10.2.481

Jorion, P., \& Zhang, G. (2007). Good and Bad Credit Contagion: Evidence from Credit Default Swaps. Journal of Financial Economics, 84(3), 860-883. http://dx.doi.org/10.1016/j.jfineco.2006.06.001

Kou, J., \& Varotto, S. (2005). Predicting Agency Rating Movements with Spread Implied Ratings. ISMA Centre Discussion Papers in Finance, DP2005-06, ISMA Centre, University of Reading, UK.

Kwan, S. (1996). Firm-specific Information and the Correlation between Individual Stocks and Bonds. Journal of Financial Economics, 40(1), 63-90. http://dx.doi.org/10.1016/0304-405X(95)00836-4

Longstaff, F. A., Mithal, S., \& Neis, E. (2005). Corporate Yield Spreads: Default Risk or Liquidity? New Evidence from the Credit Default Swap Market. The Journal of Finance, 60(5), 2213-2253. http://dx.doi.org/10.1111/j.1540-6261.2005.00797.x

Meng, L., Ap Gwilym, O., \& Varas, J. (2009). Volatility Transmission among the CDS, Equity, and Bond Markets. Journal of Fixed Income, 18(3), 33-46. http://dx.doi.org/10.3905/JFI.2009.18.3.033

Merton, R. C. (1974). On the Pricing of Corporate Debt: the Risk Structure of Interest Rates. Journal of Finance, 29(2), 449-470. http://dx.doi.org/10.1111/j.1540-6261.1974.tb03058.x

Micu, M., Remolona, E. M., \& Wooldridge, P. D. (2004). The Price Impact of Rating Announcements: Evidence from the Credit Default Swap Market. BIS Quarterly Review, 55-65. 
Norden, L., \& Weber, M. (2004). Informational Efficiency of Credit Default Swap and Stock Markets: The Impact of Credit Rating Announcements. Journal of Banking and Finance, 28(11), 2813-2843. http://dx.doi.org/10.1016/j.jbankfin.2004.06.011

Norden, L., \& Weber, M. (2009). The Co-movement of Credit Default Swap, Bond and Stock Markets: an Empirical Analysis. European Financial Management, 15(3), 529-562. http://dx.doi.org/10.1111/j.1468-036X.2007.00427.x

Parnes, D. (2012). Structural Breaks in the Current U.S. Banking Crisis. Banking and Finance Review, 4(2), 118.

Persson, M., \& Blavarg, M. (2003). The Use of Market Indicators in Financial Stability Analysis. Economic Review, 5-28.

Rahman, D. (2009). Are Banking Systems Increasingly Fragile? Investigating Financial Institutions' CDS Returns Extreme Co-Movements. Working Paper Université Paris X Nanterre, 2009-34.

Scheicher, M. (2009). The Correlation of a Firm's Credit Spread with Its Stock Price. In G. N. Gregoriou (Ed.), Stock Market Volatility (pp. 405-417). Boca Raton, Fl: Chapman and Hall/CRC Press.

Schreiber, I., Müller, G., Klüppelberg, C., \& Wagner, N. (2012). Equities, Credits and Volatilities: A Multivariate Analysis of the European Market During the Sub-prime Crisis. International Review of Financial Analysis, 24, 57-65. http://dx.doi.org/10.1016/j.irfa.2012.07.006

Silvennoinen, A., \& Teräsvirta, T. (2009). Multivariate GARCH Models. In Anderson, T. G., Davis, R. A., Kreiß, J. P., \& Mikosch, T. (Eds.), Handbook of Financial Time Series (pp. 202-229). Berlin: Springer.

Zhu, H. (2006). An empirical Comparison of Credit Spreads between the Bond Market and the Credit Default Swap Market. Journal of Financial Services Research, 29(3), 211-235. http://dx.doi.org/10.1007/s10693-006-7626-x

\section{Notes}

Note 1. The swap zero curve is usually used by derivative traders considering Libor/swap rates as the opportunity cost of capital.

Note 2. Two major groups of credit risk models are mostly used in the analysis of credit risk pricing. In structural models, default risk is handled as an endogenous process, partially accounted for by the structural factors, in contrast to reduced-form models where a firm's default cannot be anticipated and is determined by an exogenous default intensity process (Alexopoulou et al., 2009).

Note 3. CMA provides independent and accurate OTC market data (see http://www.cmavision.com).

Note 4. Similar procedures are conducted by, for instance, Longstaff et al. (2005) and Zhu (2006).

Note 5. The appropriate data for the bond yield spreads as well as the equity prices were retrieved via Thomson Reuters Datastream for all entities.

Note 6. The GARCH model was introduced by Bollerslev (1986). Due to space limitations, results of stationarity tests as well as a preliminary data analysis are not reported and are available on request.

Note 7. Results are available on request.

Note 8. Estimation results for the pre-crisis and crisis period are available on request.

Note 9. The detailed estimation results are available on request.

Note 10. Applying the Jarque-Bera test for normality to the standardized residuals, the null hypothesis of normality must be rejected for all standardized residuals due to the still remaining high kurtosis, which can often be observed in similar studies. All tests conducted for the whole sample period have also been applied to the bivariate GARCH in section 5.3. These results show the adequacy of the bivariate diagonal BEKK and are available on request.

\section{Copyrights}

Copyright for this article is retained by the author(s), with first publication rights granted to the journal.

This is an open-access article distributed under the terms and conditions of the Creative Commons Attribution license (http://creativecommons.org/licenses/by/3.0/). 